\title{
S. Bernardo (Graciliano Ramos, 1934) \& S. Bernardo (Leon Hirszman, 1972)
}

\author{
[ "S. Bernardo" (Graciliano Ramos, I934) er “S. Bernardo" (Leon Hirszman, I972)
}

\section{Nelson Tomelin Jr. ${ }^{x}$}

\begin{abstract}
Este artigo é resultado de pesquisas desenvolvidas no âmbito dos projetos Procad/Capes “Trabalho, cultura e cidade" e Universal Amazonas/Fapeam "Cidade, cultura e saúde: processos trabalhistas, modos de vida, trabalho e resistência de trabalhadores em Itacoatiara (I973-2004)”.
\end{abstract}

RESUMO - O presente artigo busca refletir sobre literatura, história e sentimentos a partir do romance S. Bernardo (I934), de Graciliano Ramos, e da adaptação dessa obra para o cinema por Leon Hirszman (I972). Pretende-se assim discutir dimensões do livro, como reflexão sobre o momento em que ele surgiu (anos I930, anúncio de "revolução" de 30 e Brasil moderno), e do filme (anos I970, ditadura civil-militar de 1964 e mais um anúncio do Brasil moderno e sem comunismo). Experiência e ambiguidade, como dimensões constitutivas das narrativas traçadas nessas duas importantes obras da cultura brasileira, são evidenciadas aqui como possibilidades de compreensão do lugar da prática e das memórias em campos históricos marcados por fortes contradições sociais. P PALAVRASCHAVE - S. Bernardo; literatura; cinema; Recebido em 26 de junho de 2017 Aprovado em I ${ }^{\circ}$ de outubro de 2018 ditadura. - ABSTRACT - The present article seeks to reflect on literature, history and feelings from the novel of S. Bernardo (I934) by Graciliano Ramos, and the adaptation of this work to the cinema by Leon Hirszman (I972). The aim is to discuss the dimensions of the book as a reflection on the moment when it emerged (I930s, I930's “revolution” and Modern Brazil), and the film (70s, civil-military dictatorship of 64 and another again announcement of modern Brazil and without communism). Experience and ambiguity, as constitutive dimensions of the narratives traced in these two important works of Brazilian culture, are evidenced here as possibilities for understanding the place of practice and memories in historical fields marked by strong social contradictions. - KEYWORDS · S. Bernardo; literature; cinema; dictatorship.

TOMELIN JR., Nelson. S. Bernardo (Graciliano Ramos, I934) \& S. Bernardo (Leon Hirszman, I972). Revista do Instituto de Estudos Brasileiros, Brasil, n. 7I, p. 2I2-23I, dez. 2018.

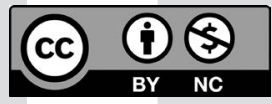

DOI: http://dx.doi.org/Io.II606/issn.23I6-9oIX.voi7Ip2I2-23I

I Universidade Federal do Amazonas (UFAM, Manaus, AM, Brasil). 
No livro S. Bernardo (RAMOS, I934) ${ }^{2}$, um personagem narrador relaciona as suas memórias à paisagem social de valorizações e desvalorizações contínuas do trabalho, sendo memória e contradição aí simultaneamente engendradas. Esse sujeito, Paulo Honório, foi criado na pobreza e se formou nos princípios da ideologia liberal do esforço próprio. Luta com os meios sociais que alcança, tendo a sabedoria dos trabalhadores, alguns desses seus companheiros nos primeiros anos de caminhada. Conhece a força bruta, mata, é preso, e espera. Trabalha como caixeiro-viajante, empresta dinheiro e toma emprestado, "ganhando aqui, perdendo ali” (RAMOS, I990, p. I4), fazendo-se com violência num mundo em que idade, peso, "as sobrancelhas cerradas e grisalhas", o "rosto vermelho e cabeludo" (é branco, capital corporal de grande importância) rendem "muita consideração" (RAMOS, I990, p. I2). Por fim, acumula recursos para adquirir as terras em que um dia serviu na enxada, S. Bernardo, e investe sem descanso na sua modernização. Envolvido na atmosfera social da crença na transformação da natureza e da humanidade em determinado ambiente, pela exploração, o prestigiado fazendeiro de Alagoas propõe casamento a Madalena, sensível professora normalista da instrução pública. É "o iniciador de uma família" (RAMOS, I990, p. I2), mas a expectativa matrimonial, de ambos, não prospera (o sentimento de ciúme e posse se manifesta como ira do marido e espancamento da esposa). Madalena finda ingerindo veneno, e Paulo Honório, "arrasado", ouvindo o choro do filho, e perdendo terras (RAMOS, I990, p. I80).

O romance de Graciliano Ramos (I892-I953), escrito no Brasil de meados dos anos

2 Acompanho neste artigo a grafia dada por Graciliano para o título do romance em I934, "S. Bernardo", a qual repete o cineasta Leon Hirszman em sua adaptação para o cinema. Vale ressaltar que os projetos editoriais que o livro recebeu posteriormente, já com o substantivo “S." por extenso na capa, preservaram no corpo do texto a forma abreviada. Com o itálico diferencio o que é texto do que é propriedade. 
I920 e início da década de $1930^{3}$, é traçado sob o signo da contradição, quando "no interior da luta de classes do período tornava-se possível a emergência de um discurso que colocava a indústria no centro de qualquer projeto político de reordenação da sociedade brasileira" (DECCA, I983, p. 69). O ímpeto liberal de Paulo Honório e a humanidade de Madalena são faces de um mesmo movimento contraditório, a industrialização do Brasil rural/moderno e o da improvável distribuição de riquezas nesse meio (os trabalhadores empregados no romance de 1934 continuam pobres no filme de I972). Serão historicamente destruídos os valores do "grande" fazendeiro da pequena e miserável Viçosa, ex-trabalhador do eito, bem como os valores da professora tardiamente "comunista", esperançosa por "vida nova" (RAMOS, I990, p. 95)4, segura para si e a tia, na propriedade privada de S. Bernardo. Ainda nesse meio, expõe a narrativa o olhar aguçado do autor sobre contradições de anúncio de "revolução" num período em que se conheciam dificuldades em torno de modelos revolucionários de estado alicerçados na divisão entre planejamento e execução (o liberalismo da "revolução" de I930 e disputas de outros grupos nacionais por esses mesmos valores em I932, além das ameaças burocráticas do pós-revolução de I9I7, já atentos para esses aspectos os críticos anarquistas daqueles momentos)5. Também Paulo Honório planeja o registro de suas memórias em livro "pela divisão do trabalho" (RAMOS, I990, p. 7), mas logo abandona a orientação classista, buscando enfrentar a divisão de si mesmo: diálogo corajoso com viventes que se reproduzem no modo de produção capitalista.

Graciliano Ramos evidencia em S. Bernardo relações sociais que são postas por práticas ambíguas, em movimentos de valorizações/desvalorizações também culturais, com difíceis divisões no campo dos sentimentos. Assim, propõe-se, aqui, uma leitura sem gatilhos interpretativos de etapas ou categorias prévias de análise, como consciência e má-consciência, humanidade e desumanidade, prosperidade e ruína, revolução e alienação, sob o risco de serem homogeneizados matizes nesse meio.

As violências e coerções constitutivas do modo de produção capitalista no

3 Em carta de Io de novembro de I932, Graciliano Ramos pondera sobre questões relacionadas ao processo e tempo de escrita da obra, sua tradução do "português" para "um brasileiro encrencado, muito diferente desse que aparece nos livros de gente da cidade, um brasileiro de matuto, com uma quantidade enorme de expressões inéditas, belezas que eu mesmo nem suspeitava que existissem. Além do que eu conhecia, andei a procurar muitas locuções que vou passando para o papel” (RAMOS, I982a, p. 134). Para referências sobre a relação entre o projeto de escrita de S. Bernardo e o conto não publicado de Graciliano Ramos intitulado "A carta" (I924), cf. Moraes, I992, p. 77.

4 Em S. Bernardo, de Leon Hirszman, a cena alcança tensa e amável estatura, com esperança no futuro pelo jovem casal Madalena e Paulo Honório (S. BERNARDO, I972, aprox. 5Imin).

5 Importante observar que muito antes de 1956 (relato de Kruschev no XX Congresso do Partido Comunista da União Soviética) já denunciavam os anarquistas, e anarcossindicalistas no Brasil, inclusive na imprensa, as mudanças de rumos por que passava a Revolução Russa com a construção de uma nova ordem burocratizante. Sobre o tema, cf. Oliveira, 2009. Sobre as críticas de anarquistas que viveram o período na União Soviética, cf. Goldman, 2007. Sobre as impressões de Graciliano Ramos quanto à "revolução" de I932, cf. Ramos, I982a, cartas 55-62 (período que coincide com o da escrita de S. Bernardo). 
Nordeste rural de $1930^{6}$, a reposição contínua das divisões sociais nesse processo, definidoras de exclusões e de misérias relacionadas à transferência de recursos, e sua concentração por uma classe encadeiam-se, reciprocamente relacionadas, por uma "estrutura de sentimentos"? em S. Bernardo. Graciliano Ramos reúne anseios afetivos e expressão semântica sintética ${ }^{8}$ através da observação acurada do tempo presente das transformações sociais que, com o fim dos anos I920 e o golpe de I930, redefinem racionalidades e políticas produtivas no país, com o ataque a modos de vida e saberes tradicionais do "Brasil moderno" do período (HARDMAN; LEONARDI, I982, p. I3I).

O romance do autor alagoano dialoga com indefinições históricas daquele processo. A estrutura de sentimentos forjada pela narrativa das experiências dos personagens de $S$. Bernardo é fonte para a pesquisa sobre formas de vida material e imaterialmente associadas no Nordeste brasileiro dos anos I9309. O cineasta Leon Hirszman recuperará tais perspectivas do romance a partir da experiência da ditadura civil-militar de I964, quando então se refinavam aqueles modernos princípios produtivos por perseguições contra dissidências e oposições políticas, com "muxicões" inúmeros nos trabalhadores rurais e urbanos, narrando-as a partir de elementos próprios à linguagem cinematográfica, com destaque para grandes planos e primoroso trabalho de atores. Tratar hoje desse tema, com o atual recrudescimento da ideologia neoliberal no Brasil, e graves ameaças à legitimidade das instituições da nossa democracia ${ }^{\text {To }}$, exige avaliação de características inerentes ao capitalismo: o roubo, a desvalorização do trabalho pela classe dominante, a contínua formação da propriedade privada, a mercadoria, "a regulamentação da ordem estatal - a separação específica entre 'público' e 'privado' - capaz de garantir a universalização das relações de produção baseadas no trabalho assalariado" (DECCA, I984, p. I52). A análise de mobilidades em meio social formador de hegemonias culturais

6 O próprio Graciliano Ramos será perseguido e encarcerado em I936 por Getúlio Vargas, experiência que relata em Memórias do cárcere, obra publicada postumamente pela editora José Olympio em I953.

7 Raymond Williams, crítico literário inglês, articula o conceito de “estrutura de sentimentos” à experiência de certas obras de arte, segundo o autor, estruturas moventes, constituídas, e simultaneamente constituintes, de consciência, de sentimentos e de linguagem, não redutíveis à estética ou à técnica, e ativamente participantes na formação social. Não circunscritas ao campo de análise de supostos "reflexos sociais", esclarece ainda o autor que "as estruturas de sentimento podem ser definidas como experiências sociais em solução, distintas de outras formações semânticas sociais que foram precipitadas e existem de forma mais evidente e imediata” (WILLIAMS, I979, p. I36). Também sobre essa categoria de análise, cf. Williams, 2002, p. 36.

8 Conforme Antonio Candido (2006, p. 2I), "a vocação para a brevidade e o essencial aparece aqui na busca do efeito máximo por meio dos recursos mínimos, que terá em S. Bernardo a expressão mais alta”. No reverso das palavras de Paulo Honório/Graciliano: “Há por aí volumes que cabem em quatro linhas” (RAMOS, I990, p. 92).

9 Articulações interpretativas importantes sobre história, política e estética no campo temático literatura $e$ sociedade dos anos 30, evidenciando “diferentes relações que se estabelecem entre o 'livro' e o realismo rural no romance S. Bernardo", podem ser conferidas em: Alves, 2015.

Io Sobre o golpe de estado de 20I6, cassação do mandato da presidenta Dilma Roussef (20I5-20I9) e ameaças em curso contra a classe trabalhadora brasileira, cf. Cardozo, 2016. 
requer, no entanto, atenção redobrada para movimentos contra-hegemônicos ${ }^{\mathrm{II}}$, com ambiguidades, também de sentimentos, definidas numa relação contraditória, portanto, de experiências em disputa: nas palavras de Raymond Williams (I979, p. I36), "em solução".

Williams, em O campo e a cidade: na história e na literatura, estudo que analisa contradições ideológicas em abstrações sobre a "metrópole" e do "mundo rural inglês", indica dimensões investigativas que podem ser observadas na leitura de $S$. Bernardo e sua adaptação para o cinema. Lembra o crítico, sobre a "estrutura geral de sentimentos" e potencial problematizador de obras literárias da Inglaterra do século XIX, que "seria muito menos convincente se não houvesse nada além de alienação, frustração, separação e isolamento, catástrofes finais” (WILLIAMS, 20II, p. 352). Sobre visão "amarga e sombria" de autores do período, identifica o crítico literário perspectivas que sinalizam que

[...] a única saída é reservada ao indivíduo excepcional; seu destino, contudo, é uma mobilidade árdua e ambígua, na qual, na maioria das vezes, ele ou sucumbe após anos de esforço, ou prospera, porém deteriora moralmente, pois as únicas maneiras de chegar ao sucesso partindo de uma situação geral destrutiva levam à exploração do trabalho ou das mentes dos outros, e essa exploração só é possível graças à estupidez, indiferença ou brutalidade dos explorados. (WILLIAMS, 20II, p. 369).

As memórias de S. Bernardo são o produto da trajetória de um homem que se relaciona com valores humanos diversos, expressos em meio a fortes contradições e interesses, com camadas afetivas e sociais intermediárias aos extremos de "declínio" e "ascensão". O narrador Paulo Honório, homem branco, foi pobre, levou puxões de orelha como guia de cego, e teve como mãe adotiva uma ex-escrava. Posteriormente, trabalhou pela consolidação de uma propriedade, adquirindo-a por golpes de juros e depreciações ameaçadoras, contra, é preciso lembrar, a família rica do falecido patrão que um dia o explorou no eito: Salustiano Padilha, primeiro proprietário de S. Bernardo (então engenho de "fogo morto").

Paulo Honório, "um enjeitado" (CANDIDO, I978, p. I03), filho de pais incógnitos, "trabalhador alugado" (RAMOS, I990, p. 20), até os I8 anos na enxada, que conheceu "surra de cipó de boi”, e o cárcere, "três anos, nove meses e quinze dias", foi “o iniciador de

II A partir de instigante leitura de Antonio Gramsci, Raymond Williams (I979 apud CHAUI, I986, p. 22), em Marxismo e literatura, observa que uma "hegemonia viva é sempre um processo. Não é, senão do ponto de vista analítico, um sistema ou uma estrutura. É um complexo realizado de experiências, relações, atividades com pressões e limites específicos e mutáveis. Na prática, a hegemonia nunca pode ser singular. Suas estruturas concretas são altamente complexas e, sobretudo (o que é crucial), não existe apenas passivamente na forma da dominação. Deve ser continuamente renovada, recriada, defendida e modificada e é continuamente resistida, limitada, alterada, desafiada por pressões que não são suas. Nesse sentido, devemos acrescentar ao conceito de hegemonia os conceitos de contra-hegemonia e hegemonia alternativa, que são elementos reais e persistentes da prática”. (A tradução de Marilena Chaui parece atingir com maior precisão as reflexões do autor nesse trecho, podendo ser cotejada com a edição brasileira da obra em: Williams, I979, p. II5.) Para aprofundar o tema, cf. Gramsci, 2015. 
uma família” (RAMOS, I990, p. I2-I3). Desbanca vizinhos de cerca: "Pensei no Mendonça. [...] Quantas braças de terra aquele malandro tinha furtado!” (RAMOS, I990, p. 33).

Raymond Williams, na obra referida acima, examina a composição da escrita de autores ingleses que presenciaram violentos processos históricos na disputa fundiária, tais como aqueles vividos no meio social do narrador de $S$. Bernardo: “cercamentos”, "heranças”, “as migrações sazonais”, “as feiras de contratação de trabalhadores”, "o pároco intelectualmente arrogante”, "a ética do melhoramento” das terras ${ }^{\mathrm{I2}}$, "a queda de uma família e a ascensão de outra [...] história geral - e cruel - da propriedade e de suas consequências para aqueles que a ela eram sujeitados, um processo secular" (WILLIAMS, 20II, p. 347). S. Bernardo encarna dialógica "estrutura de sentimentos", vinculada nesse entremeio pela costura de desejos, amor, classe, e sofrimentos, pelo trabalho social da memória ${ }^{\text {I3 }}$, reciprocamente relacionados o campo histórico dessa narrativa, os sujeitos e a sua classe, que "como qualquer outra relação, é algo fluido que escapa à análise ao tentarmos imobilizá-la num dado momento e dissecar sua estrutura” (THOMPSON, I997, p. Io).

Graciliano e igualmente Leon Hirszman expõem em $S$. Bernardo leitura não estática do que seja uma "classe", ainda nas palavras do historiador inglês E. P. Thompson, "um fenômeno histórico", "algo que ocorre efetivamente (e cuja ocorrência pode ser demonstrada) nas relações humanas”, "encarnada em pessoas e contextos reais", "que unifica uma série de acontecimentos díspares e aparentemente desconectados, tanto na matéria-prima da experiência como na consciência” (THOMPSON, I997, p. 9-Io). Graciliano Ramos, estudioso do marxismo (o autor dos anos I930 não seria, contudo, o mesmo que escreveu Viagem), observou criticamente dicotomias entre teoria e prática social ao longo de sua obra, chegando a postular perspectivas de avanços humanos criados e disseminados mundo afora a partir de valores revolucionários, atento, contudo, para contraditórias experiências nesse

I2 Raymond Williams deu importante contribuição para a análise da "ética do melhoramento" na Inglaterra do século XVIII, a modernização racional da terra, período em que o capitalismo agrário já consolidara como "uma estrutura cada vez mais regular de arrendatários e trabalhadores assalariados”, ampliando compreensões no campo da literatura sobre a formação histórica da condição do assalariamento e da conquista liberal do meio. Observa Williams que "uma ideologia do melhoramento - da transformação e organização da terra - tornou-se importante e dominante. As relações sociais que constituíam obstáculos a essa forma de modernização começaram a ser gradualmente destruídas, por vezes de forma impiedosa”. Tais processos de valorização e desvalorização social criavam, "através de cercamentos e anexações de terrenos que visavam formar grandes unidades lucrativas, um número maior de pessoas sem terra e deserdadas, que não podiam sobreviver nem competir nas novas circunstâncias” (WILLIAMS, 20II, p. IO4-II4).

I3 Para a discussão sobre a memória como objeto de estudo e dimensão da prática política, cf. Grupo Memória Popular, 2004. 
campo (cf. RAMOS, 2007) I4. Articulado ao meio social de sua experiência, Paulo Honório tece com ironia críticas a Costa Brito e a Padilha: o primeiro, jornalista suspeito, o outro, herdeiro fanfarrão, posteriormente "revolucionário" (RAMOS, I990, pp. 85 e I74). Madalena será também lembrada aí: "Comunista, materialista. Bonito casamento!" (RAMOS, I990, p. I3I). O personagem Padilha, muito bem interpretado na adaptação de Leon Hirszman pelo ator Nildo Parente, tem realçado traços de suavidade, ligação com a terra, sentimentos (S. BERNARDO, I972, aprox. 8min50s).

A problematização que aqui se propõe para o campo narrativo das disputas sociais de $S$. Bernardo acompanha E. P. Thompson ao entender com ele que "a mais fina rede sociológica não consegue nos oferecer um exemplar puro de classe, como tampouco um do amor ou da submissão. [...] Não podemos ter amor sem amantes, nem submissão sem senhores rurais e camponeses" (THOMPSON, I997, p. I0) ${ }^{\text {I5 }}$.

Paulo Honório e Madalena, modesta professora primária em Viçosa/Alagoas, arranjam casamento e têm um filho. Entre perseguições autoritárias do marido, confrontos com a própria consciência, a difícil convivência com a condição de vida precária dos moradores da fazenda, e o apaziguamento espiritual pela segurança permitida à tia que a criara com dificuldade econômica extrema, suicida-se: "Seja amigo de minha tia, Paulo. Quando desaparecer essa quizília, você reconhecerá que ela é boa pessoa" (RAMOS, I990, p. I6I). Já envelhecido, aos 50 anos, finada Madalena naquelas violências e contradições, e arruinados os negócios pela "revolução" de I930 (cf. JUAREZ FILHO, 2006) ${ }^{\mathrm{T}}$, busca o narrador recompor-se, escrevendo, "à mesa da sala de jantar, fumando cachimbo e bebendo café” (RAMOS, I990, p. IO), servido pela cozinheira Maria das Dores, e por Casimiro Lopes, que da varanda lhe faz a segurança.

Paulo Honório alcançou estatura e privilégios naquela sociedade dividida em classes, concorrendo para isso com recursos históricos: "Violências miúdas passaram despercebidas. As questões mais sérias foram ganhas no foro, graças às chicanas de João Nogueira”, seu advogado (RAMOS, I990, p. 40). A influência sobre a imprensa noticiosa, e a religião, o fazendeiro ajustava com Gondim e Padre Silvestre. Transcorridos dois anos da morte de Madalena, sem os amigos, que "deixaram de vir

I4 Nessa obra, publicada em I954, o autor relata viagem de dois anos antes ao bloco soviético, como membro do Partido Comunista Brasileiro e presidente da Associação Brasileira dos Escritores. Graciliano, avesso a camisas de força ideológicas, reconhece avanços verificados no campo das políticas públicas por cidadania naqueles países, bem como critica contradições de classe e controles burocráticos observados, sem "insinuar que, em trinta e cinco anos, a revolução de outubro haja criado um paraíso, com as melhores navalhas de barba, as melhores fechaduras e o melhor mataborrão" (RAMOS, 2007, p. II).

I5 Em estudo de referência sobre Graciliano Ramos, e por outros vieses analíticos, Carlos Nelson Coutinho lê $S$. Bernardo por categorias reflexivas que destacam sínteses narrativas em torno da "construção de um burguês" e a "necessária tragédia do individualismo" daquela classe, com destaque para a "alienação" do personagem Paulo Honório em "interesse egoísta”, reduzidos os homens a "instrumentos de sua ambição, meios que ele utiliza para a obtenção do fim, da realização individual a que se propõe” (COUTINHO, I967, p. I53 e I80).

I6 Como importante referência sobre formações ideológicas no período, cf. Chaui, I985. Na historiografia, I930 aparece como tema que enfeixa a ideologia da industrialização e da memória histórica do desenvolvimento relacionadas a perspectivas de planejamento racional da sociedade. Sobre o tema, cf. Decca, I984, e Vesentini, I997. 
discutir política” (RAMOS, I990, p. I79), o narrador inicia a composição da sua dor e humanidade, a narrativa de $S$. Bernardo.

Sublinha Antonio Candido, a respeito do romance S. Bernardo, "a humanidade singular" do protagonista, sobreposta aos "fatores do enredo: meio social, paisagem, problema político", concepção literária que determina “o importantíssimo caráter de movimento dessa fase do romance, que aparece como instrumento de pesquisa humana e social, no centro de um dos maiores sopros de radicalismo da nossa história”, segundo o crítico, o período que se segue a I930 (CANDIDO, I980, p. I23-I24).

$\mathrm{Na}$ obra do escritor alagoano, e não apenas no referido romance, a força capitalista estruturante do social se espraia em relações históricas constitutivas de hegemonias e contra-hegemonias, com oposições, resistências, cumplicidades, interiorização e subordinação (CHAUI, I986, p. 22-23). Seria pouco reunir conclusivas interpretações quanto a ser Paulo Honório proprietário, ou reduzi-lo a imperativos sentimentais dominantes: o ciúme que tem de Madalena. Antes, esse sentimento bem como a produção são dimensões de apropriação, eventualmente cingidas pelo “absurdo” (RAMOS, I990, p. I04), mas humanas. De todo modo, como observa Marx, a apropriação não é necessariamente determinada pela propriedade privada, sendo antes condição de qualquer produção, mesmo do amor ${ }^{\mathrm{T} 7}$. Madalena, d. Glória e Paulo Honório, trabalhadores que viveram enormes privações, decidem constituir uma família, e morar juntos, pois "onde comem dois comem três. E a casa é grande, tem uma porção de caritós” (RAMOS, I990, p. 94).

Os duelos internos de Paulo Honório são travados em relação simultânea e ambígua no tempo presente de suas lembranças e imagens do passado ${ }^{18}$, o "teatro da memória” de que nos fala Raphael Samuel ${ }^{\text {I9. }}$. A força estreita que orienta o fazendeiro, violência de classe, na conquista da terra e do trabalho alheio - a exploração de Marciano, Rosa, mestre Caetano, e demais trabalhadores de S. Bernardo - alcança perspectivas ampliadas na construção dessas memórias. Não foram só os desamores oriundos da relação com Madalena que lhe corroeram o ímpeto produtivo, mas também o movimento de desvalorização social então criado a partir de disputas dentro de sua própria classe: "Ainda por cima os bancos me fecharam as portas. Não sei por que, mas fecharam. E olhem que nunca atrasei pagamentos. Enfim uma penca de caiporismos” (RAMOS, I990, p. I78). Segundo destaca Antonio Candido: “A bondade

I7 “Toda produção é apropriação da natureza pelo indivíduo no interior de e mediada por uma determinada forma de sociedade. Nesse sentido, é uma tautologia afirmar que propriedade (apropriação) é uma condição da produção. É risível, entretanto, dar um salto daí para uma forma determinada de propriedade, por exemplo, para a propriedade privada. (O que, além disso, presumiria da mesma maneira uma forma antitética, a não propriedade, como condição)" (MARX, 20II, p. 43).

I8 Marilena Chaui (I986, p. I23) aponta como ambígua “a forma de existência dos objetos da percepção e da cultura”, constituídas “não de elementos ou de partes separáveis, mas de dimensões simultâneas”. A partir de Merleau-Ponty, observa, no entanto, que tais ambiguidades "somente serão alcançadas por uma racionalidade alargada, para além do intelectualismo e do empirismo". Para o aprofundamento de discussões propostas por Merleau-Ponty nessa direção, cf. Merleau-Ponty, 2005.

I9 Trata-se de expressão a partir da qual Raphael Samuel (I997) problematiza o tema da memória no campo da pesquisa em história social. 
humanitária de Madalena ameaça a hierarquia fundamental da propriedade e a couraça moral com que foi possível obtê-la. O conflito se instala em Paulo Honório, que reage contra a dissolução sutil da sua dureza" (CANDIDO, 2006, p. 37). De todo modo, também Madalena vivencia sentimentos ambíguos nesse romance, como o desânimo pelo filho: "a ama vivia meio doida de sono" (RAMOS, I990, p. I36), e o compromisso tangencial com a própria profissão: "Foi à escola, criticou o método de ensino do Padilha e entrou a amolar-me [...]” (RAMOS, I990, p. I07).

Necessário não esquecer, contudo, que as memórias de $S$. Bernardo (romance e filme) são as de Paulo Honório, quem nos apresenta os demais "viventes" e as ambiguidades de fazeres sociais pelos quais se relacionam naquele lugar. Imprevisibilidades no processo histórico de instituição da propriedade em $S$. Bernardo alinham toda a trama em torno da trajetória pessoal, e força social, de Paulo Honório, proprietário miúdo em disputa com maiores por espaço. Nesse romance, o "bicho do subterrâneo" (CANDIDO, I978, p. 95) reúne contradições do seu meio. Como observa Antonio Candido, constitui "essencialmente uma pesquisa progressiva da alma humana, no sentido de descobrir o que vai de mais recôndito no homem". E essa experiência se desenrola num mundo conhecido, o do capitalismo e da degradação extrema, exploração de homens e mulheres em terras e vidas secas, de muitos Fabianos, Sinhás Vitória, Paulos Honório, injustas contas e cercas, contestação de direitos, migração, além de esperança, desejo de parada (cf. RAMOS, 20Io). Também o proprietário de S. Bernardo percorreu caminhos difíceis e secos: "Resolvi estabelecer-me aqui na minha terra, Viçosa, Alagoas, e logo planejei adquirir a propriedade S. Bernardo, onde trabalhei, no eito, com salário de cinco tostões" (RAMOS, I990, p. I5).

Em S. Bernardo, Paulo Honório nos informa que saem as suas memórias publicadas sob pseudônimo, com um deslocamento narrativo da sua condição de personagem-autor para a de sujeito histórico (Graciliano Ramos) ${ }^{20}$, abrindo passagem para um diálogo próximo com o leitor do livro, com quem compartilha o campo social, modo de vida e contradições que aí se evidenciam. Tem aí o romance a condição de história do tempo presente. Os leitores de Paulo Honório conversam com ele enquanto compõe o texto, chegando mesmo a questioná-lo: "- Então para que escreve?”. “- Sei lá!”, responde o narrador (RAMOS, I990, p. II).

Paulo Honório conheceu a hegemonia de classe, e foi agressivo nessas disputas. Negou, entretanto, sentidos prontos de justiça e honestidade em meio social de

20 Sem a intenção de associar imediatamente vida e obra, ou justificar desdobramentos de uma na outra, cito, como curiosidade, trecho de carta do autor, de 20 de agosto de I932, endereçada à esposa, Heloísa Ramos, em que relata o seu cotidiano no período em que escrevia S. Bernardo: "Durante o dia converso com seu Ribeiro, com Azevedo Gondim, com o Padilha e com a Madalena. São os companheiros que aqui estão sempre, mas as conversas deles estão-se tornando muito cacetes. Estive um dia em Viçosa e encontrei aquilo transformado. Possibilidade de arranjar qualquer coisa lá - nenhuma. Nem lá nem aqui. Tudo cavado. O que é necessário é esperar o fim da encrenca de S. Paulo. Meter-me em negócio no meio desta atrapalhação é burrice. Estou cansado de fazer coisas incompletas. Vou aguardar o resultado da luta no sul para depois orientar-me. E enquanto não me oriento, conserto as cercas de S. Bernardo, estiro o arame farpado, substituo os grampos velhos por outros novos e, à noite, depois do rádio, leio a Gazeta de Costa Brito” (RAMOS, I982a, p. I2O-I2I). 
terríveis exclusões. Foi caixeiro-viajante, "marchando no fiado" pelas Alagoas, realizando "embrulhadíssimas" transações, "com gente que fala aos berros", "de armas engatilhadas" (RAMOS, I990, p. I4).

A tessitura com que Graciliano Ramos constrói a narrativa de S. Bernardo é engendrada em diálogo com a trama histórica das mudanças e transformações do capitalismo agrário. Um "caminho" que supostamente se perfaz "na venda" (RAMOS, I990, p. Io), narrado em tom de cumplicidade, mas que o trabalho de "composição" do escritor Paulo Honório avança, valendo-se dos "próprios recursos e sem indagar se isto me traz qualquer vantagem, direta ou indireta" (RAMOS, I990, p. 9-Io). Importante enfatizar que avulta em sua narrativa a memória das discordâncias de Madalena com a exploração dos trabalhadores de S. Bernardo.

\section{S. BERNARDo, CULTURA E TRABALHO}

As análises do presente artigo acompanham ainda perspectivas sugeridas por Antonio Candido em Ficção e confissão: ensaios sobre Graciliano Ramos (I955), tendo observado o crítico sobre $S$. Bernardo a capacidade da síntese que reúne forma e conteúdo, o ser social e a experiência ${ }^{21}$. Sobre o "sentimento de propriedade" de Paulo Honório, observou que "mais do que simples instinto de posse, é uma disposição total do espírito, uma atitude geral diante das coisas". Tendo definido aquele romance como "estudo patológico de um sentimento", observou ainda Antonio Candido que Graciliano teria partido do "pressuposto de que a maneira de viver condiciona o modo de ser e de pensar". Lembra, contudo, que "não se trata, evidentemente, do resultado mecânico de certas relações econômicas. Uma profissão, ou ocupação qualquer, é um todo complexo, integrado por certos impulsos e concepções que ultrapassam o objetivo econômico" (CANDIDO, 2006, p. 39). Antonio Candido relaciona, assim, como cultura, dimensões subjetivas, trabalho e fazeres sociais.

Graciliano Ramos apresenta um personagem-escritor que conhece o trabalho e a criação com a terra, no Nordeste do primeiro quartel do século XX, bem como a dificuldade de escapar da exploração nesse meio: "Tudo isso é fácil quando está terminado e embira-se em duas linhas, mas para o sujeito que vai começar, olha os quatros cantos e não tem em que se pegue, as dificuldades são terríveis" (RAMOS, I990, p. II ${ }^{22}$. Paulo Honório reconhece parceiros que, assim como ele, consumiram-se nessa "empresa". Com Margarida, sua mãe preta, trabalhou e viveu a infância. No "tacho velho" da doceira, no "centro da pequena casa onde vivíamos. Mexi-me em redor dele vários anos, lavei-o, tirei-lhe com areia e cinza as manchas de azinhavre

2I Análise aprofundada sobre a técnica narrativa que nesse romance imbrica personagem e ação, cf. em Lafetá, I990, p. I92.

22 O tema da experiência aparece na obra e trajetória pessoal de Graciliano Ramos como dimensão de diálogo e relação com o seu lugar social e político, com trabalho de escrita que dimensiona a dialética no campo das contradições vividas, revalorizando homens e mulheres invisibilizados pela sociedade de classes (RAMOS, I970). Para mais discussões sobre o conceito de experiência a partir das trajetórias de sujeitos históricos ocultados no campo das ciências sociais, cf. Thompson, I98I, p. I80. 
- e dele recebi sustento. Margarida utilizou-o durante quase toda a vida. Ou foi ele que a utilizou" (RAMOS, I990, p. 58).

O romance $S$. Bernardo trata de ponderações de um narrador sobre aspectos de uma nova experiência, a produção de uma memória: "Quanto às vantagens restantes - casas, terras, móveis, semoventes, consideração de políticos, etc. - é preciso convir em que tudo está fora de mim" (RAMOS, I990, p. I83). A sua escrita é tentativa de reencontro com dimensões vividas, consideradas à luz das alterações constitutivas do homem que se tornou: "fecho os olhos, agito a cabeça para repelir a visão que me exibe essas deformidades monstruosas" (RAMOS, I990, p. I87) ${ }^{23}$. S. Bernardo, a experiência derradeira de Paulo Honório, resguarda compreensão importante sobre as contradições que marcaram a sua trajetória, engendrado o seu mundo social juntamente com as suas expressões pensadas: "Para ser franco, declaro que esses infelizes não me inspiram simpatia. Lastimo a situação em que se acham, reconheço ter contribuído para isso, mas não vou além. Estamos separados! A princípio estávamos juntos, mas esta desgraçada profissão nos distanciou" (RAMOS, I990, p. I87). Ideológico seria procurar "dentro" de Paulo Honório um outro "eu”, ou mais "humano" na origem, ou conspurcado no tempo. Graciliano Ramos não dialogou com tais dicotomias: antes refletiu sobre amor $e$ morte, além de outras contradições.

Relações ambíguas são constitutivas da narrativa de Paulo Honório. Casimiro Lopes, o capataz de S. Bernardo, é a expressão acirrada de violências eventualmente ocultadas por contratos "legais" no capitalismo. O "justo" e o "injusto" ganham relatividade histórica nesse personagem. Diz-lhe Marciano: “- [...] A gente se mata por causa dos outros. É ou não é, Casimiro? Casimiro Lopes franziu as ventas, declarou que as coisas desde o começo do mundo tinham dono" (RAMOS, I990, p. 60). Paulo Honório e Casimiro Lopes são personagens formados mutuamente: "Continuei a estirar o arame farpado e a substituir os grampos velhos por outros novos. Mendonça, de longe, ainda se virou, sorrindo e pregando-me os olhos vermelhos. À tarde, quando voltei para casa, Casimiro Lopes acompanhou-me, carrancudo" (RAMOS, I990, p. 28). A ordem que aos dois uniu é "desta vida agreste" (RAMOS, I990, p. IO2). A caminhada de Paulo Honório - suas pretensões na vida, "ganhar dinheiro" e apossar-se das terras de S. Bernardo - é refeita ao lado do capanga, a partir de episódio de força contra um devedor, quando “o capital se desviava” (RAMOS, I990). Acompanhado de Casimiro, modifica então históricas e desfavoráveis correlações de força:

Está um exemplo. O dr. Sampaio comprou-me uma boiada, e na hora da onça beber água deu-me com o cotovelo, ficou palitando os dentes. Andei, virei, mexi, procurei empenhos - e ele duro como beira de sino. Chorei as minhas desgraças: tinha obrigações em penca, aquilo não era trato, e tal, enfim, etc. O safado do velhaco, turuna, homem de facão grande no município dele, passou-me um esbregue. Não desanimei: escolhi uns rapazes em Cancalancó e quando o doutor ia para a fazenda caí-lhe em cima, de

23 Walter Benjamin observa a relação entre o declínio da experiência e o fim do papel social do narrador. Não mais relacionado a partir do contato próximo com as pessoas, por vivências nesse meio, o narrador perde a sua função, desfazem-se as perspectivas dialógicas da sua memória (BENJAMIN, I996, p. I97-22I). 
supetão. Amarrei-o, meti-me com ele na capoeira, estraguei-lhe os couros nos espinhos dos mandacarus, quipás, alastrados, e rabos-de-raposa.

- Vamos ver quem tem roupa na mochila. Agora eu lhe mostro com quantos paus se faz uma canoa.

O doutor, que ensinou rato a furar almotolia, sacudiu-me a justiça e a religião.

- Que justiça! Não há justiça nem há religião. O que há é que o senhor vai espichar aqui trinta contos e mais os juros de seis meses. Ou paga ou eu mando sangrá-lo devagarinho.

Dr. Sampaio escreveu um bilhete à família e entregou-me no mesmo dia trinta e seis contos e trezentos. Casimiro Lopes foi o portador. Passei o recibo, agradeci e despedi-me: - Obrigado, Deus o acrescente. Sinto muito ter-lhe causado incômodo. Adeus. E não me venha com a sua justiça, porque se vier, eu viro cachorro doido e o senhor morre na faca cega. (RAMOS, I990, pp. I4-I5).

O fazendeiro, sentimentalmente distante do filho, lembra de carinhos do capanga com a criança: "a única pessoa que lhe tinha amizade. Levava-o para o alpendre e lá se punha a papaguear com ele, dizendo histórias de onças, cantando para o embalar as cantigas do sertão. O menino trepava-lhe às pernas, puxava-lhe a barba, e ele cantava” (RAMOS, I990, p. I36). A mesma cantiga mencionada nessa passagem de S. Bernardo é referida em Infância (I945). O autor lembra de José Baía no primeiro capítulo daquelas suas recordações, "um rapagão aprumado e forte", nordestino "pobre" (RAMOS, I982b, p. I2). Define-o como seu amigo:

Sentado, escanchava-me nas pernas e sacudia-me, sapateava, imitando o galope de um cavalo; em pé, segurava-me os braços, punha-se a rodopiar, cantando:

Eu nasci de sete meses,

Fui criado sem mamar.

Bebi leite de cem vacas,

Na porteira do curral. (RAMOS, I982b, p. I2) ${ }^{24}$.

Também o carinho do fazendeiro por Madalena envolve escolhas próprias, mais do que interesses reprodutivos, ou sua continuidade pela herança. A professora é escolhida no lugar da filha do juiz dr. Magalhães: d. Marcela, um "bichão. Uma peitaria, um pé-de-rabo, um toitiço!” (RAMOS, I990, p. 68). A verdade de relações pessoais como aquela se perde em cálculos imprecisos, como o seu sentimento por Margarida, redescoberta em “Jacaré-dos-Homens, Pão-de-Açúcar” após décadas de busca, com a ajuda de "anúncio do Cruzeiro" (RAMOS, I990, p. 49). Apresentam-se correntes contra-hegemônicas na narrativa de S. Bernardo, costuradas também no

24 As memórias de Paulo Honório se constituem em espaço de recordações sociais não estranho a vivências do próprio autor Graciliano Ramos. O autor viveu importante período da sua infância e juventude em Viçosa, sua terra dos 7 aos 18 anos de idade. Antes disso, em Buíque (PE), conhecera um sitiante chamado Paulo Honório (RAMOS, I982b, p. 49). 
tempo futuro, de esperanças não represáveis pela racionalidade ${ }^{25}$. Paulo Honório traz a mãe negra já cega para perto de si, com estimativa de gastos, mas sem contrapartida de ganhos: "A velha Margarida mora aqui em S. Bernardo, numa casinha limpa, e ninguém a incomoda. Custa-me dez mil-réis por semana, quantia suficiente para compensar o bocado que me deu" (RAMOS, I990, p. I2-I3). Antonio Candido (2006, p. 34) sublinha da passagem a única vez em que age o fazendeiro "em obediência ao sentimento de gratidão", mas que "ainda aí as relações afetivas só se concretizam numericamente". Para o enterro de Margarida, trabalhadora de um século de vida, Paulo Honório reserva lugar no "altar-mor da capela" da propriedade, perto de Madalena (RAMOS, I990, p. I3 e I66). O processo de construção desses afetos e de suas manifestações, na obra de Graciliano Ramos, expressa dimensão humana de sentimentos difíceis naquele campo de sonhos e vidas agrestes ${ }^{26}$.

Em S. Bernardo, como em outras de suas obras, Graciliano Ramos rejeita o que Marilena Chaui, em Conformismo e resistência, identifica depois como "a ideologia sociológica da 'mobilidade social", a "garantia" de "que qualquer membro da massa pode 'subir' à elite, desde que seja um indivíduo excepcional” (CHAUI, I986, p. 29). Paulo Honório ascende pela força, violência e corrupção intrínsecas ao modo de produção capitalista, sem excepcionalidades. A sua história é a da reinvenção de S. Bernardo, empresa falida, por relações de aproximação com o poder e a imprensa, explorações terríveis, e atentados, sem deixar de avaliar caminhos supostamente alternativos naquele espaço social de fortes imposições: "Julgo que me desnorteei numa errada" (RAMOS, I990, p. I83). Madalena também foi pobre e, no encalço daquela força do fazendeiro, ascendeu: “- Parece que nos entendemos. Sempre desejei viver no campo, acordar cedo, cuidar de um jardim. Há lá um jardim, não?” (RAMOS, I990, p. 93). Igualmente, a trajetória de seu Ribeiro ${ }^{27}$ (contador da fazenda) materializa o enlace de transformações e lutas entre interesses antagônicos: "Na povoação onde ele morava os homens descobriam-se ao avistá-lo e as mulheres baixavam a cabeça e diziam:-Louvado seja Nosso Senhor Jesus Cristo, seu major" (RAMOS, I990, p. 35). Seu Ribeiro perdeu o seu lugar, fugiu-lhe o prestígio, e empobreceu. Foi substituído por outra racionalidade, o capitalismo, difícil de acompanhar, "com crises de crédito e de preços", submetida "a economia às disciplinas do trabalho assalariado e do mercado" (WILLIAMS, 20II, p. 304). Nas palavras de Paulo Honório: “- Tenho a impressão de

25 Faço referência aqui à importante análise de Déa Ribeiro Fenelon (2009, p. 28) sobre “as ideias de progresso, racionalidade, desenvolvimento, que marcaram o avanço do capitalismo e as análises sobre as concepções do social”. Como referência de outras discussões críticas nessa linha, cf. Chaui, 2003.

26 Em outro livro do autor, Vidas secas (RAMOS, 20Io), o tema das relações afetivas também aparece sob a marca da ambiguidade. Fabiano, Sinhá Vitória e filhos, migrantes pobres ameaçados pelo latifúndio, vivem experiência de sentimentos contraditórios em torno da morte da cadela Baleia. As ambivalências em torno dessa passagem foram destacadas pelo diretor Nelson Pereira dos Santos em sua adaptação da obra para o cinema. Cf. o filme Vidas secas, I963.

27 Importante análise da relação do "par” Paulo Honório e seu Ribeiro, compreendendo como aí representadas disputas entre a modernização e a pequena aristocracia rural anterior a I930, pode ser conferida em Bastos, 20I5, p. 25. 
que o senhor deixou as pernas debaixo de um automóvel, seu Ribeiro. Por que não andou mais depressa? É o diabo" (RAMOS, I990, p. 38).

A análise desses processos, de consequências sociais amplas, é recorrente na obra de Graciliano. Em “A decadência de um senhor de engenho" (RAMOS, I970, p. II5), sobre a ruína de Joaquim Pereira, vivente rijo e imóvel, "tão rijo e tão imóvel como os esteios da casa-grande, que principiavam a bichar, teve um fim lastimável. Precisou mexer-se, desejou transplantar-se, mas estava seco e não criou raízes. [...] E os seus descendentes acabaram também no caruncho e na miséria” (RAMOS, I970, p. II8). No caso de seu Ribeiro, "o povoado transformou-se em vila, a vila transformou-se em cidade, com chefe político, juiz de direito, promotor e delegado de polícia. [...] E impostos" (RAMOS, I990, p. 37). Paulo Honório conhece o "major" em Maceió, empregado "na Gazeta do Brito" (RAMOS, I990, p. 35). Oferece-lhe o serviço de "guarda-livros" em S. Bernardo e leva-o consigo. O processo histórico que desaloja seu Ribeiro de sua "casa grande", e fragmenta a sua família, é o mesmo que edifica e melhora a lavoura de Paulo Honório, tanto quanto o arruinará logo adiante.

\section{S. BERNARDO, EXPERIÊNCIA E MEMÓRIA}

Leon Hirszman (I937-I987), diretor do filme S. Bernardo (I972) ${ }^{28}$ - além de realizações como Pedreira de São Diogo, episódio do filme coletivo Cinco vezes favela (I962), Cantos de trabalho: mutirão, cana-de-açúcar, cacau (I974-1976), Eles não usam black-tie (I98I) e Imagens do inconsciente (I983-I986) -, apostou em seu próprio trabalho na revalorização dos fazeres sociais da classe trabalhadora. O cineasta inicia a sua narrativa de S. Bernardo - segundo Antonio Candido (20II), a mais bem-sucedida adaptação da literatura para o cinema no Brasil - com experimentação vocal de

28 Ficha técnica: S. Bernardo (filme 35 mm), I972, IIo min., color. Direção, argumento e roteiro: Leon Hirzman; produção: Marcos Farias; assistente de direção: Lúcio Lombardi; fotografia: Lauro Escorel; câmera: Cláudio Portioli; montagem: Eduardo Escorel; música: Caetano Veloso; locação: Viçosa, estado de Alagoas; companhia produtora: Saga Filmes, Mapa Filmes e Produções Cinematográficas, L. C. Barreto; distribuidora: Embrafilme; laboratório: Líder Cinematográfica; elenco: Othon Bastos (Paulo Honório), Isabel Ribeiro (Madalena), Nildo Parente (Padilha), Vanda Lacerda (dona Glória), Mário Lago, Jofre Soares (padre), Rodolfo Arena, Josef Guerreiro, Audrey Salvador, José Policena, José Lucena, Ângelo Labanca, Luiz Carlos Braga. Sofrendo os reveses da Censura Federal pela ditadura civil-militar de I964, atrasa sete meses a estreia de S. Bernardo, em razão de dificuldades financeiras da produtora Saga Filmes, e sua consequente falência, com execuções judiciais que se arrastam até 1977, levando Leon Hirszman a cogitar o seu desligamento da atividade artística. Cf. Cardenuto, 20I4, e Davi, 20Io. O romance S. Bernardo teve ainda adaptação para a televisão por Lauro César Muniz (Rede Globo, I984), com direção de Paulo José, e atuação de José Wilker, Regina Duarte, Nildo Parente, Beatriz Segall, Tonico Pereira. 
Caetano Veloso ${ }^{29}$ em ritmo de canto de trabalho e carro de boi (mescla de aboio e lamento), e imagem do verso de uma cédula de cinco mil-réis que emerge do nome da propriedade vazado na tela, finalmente preenchendo o dinheiro todo o espaço. Com figuras impressas de ninfas, anjo, natureza, roldana e martelo, alegoria da indústria e do comércio, produção e reprodução aparecem relacionadas nessa abertura. S. Bernardo dialoga com a beleza da palavra dita, em expressivas interpretações de atores e atrizes (Othon Bastos, Isabel Ribeiro, Mário Lago, Vanda Lacerda) comprometidos com a resistência naquele momento de acirramento da luta de classes pela ditadura civil-militar no país (I964-I985). O carinho e delicadeza com que os atores protagonistas se tratam na sequência em que Paulo Honório e Madalena decidem pelo casamento, e mudança para a fazenda, talvez seja uma das mais notáveis interpretações da história do cinema, pelo entendimento histórico alargado daqueles intérpretes (cf. S. BERNARDO, I972, aprox. 43-5Imin) ${ }^{30}$. As terríveis pressões da ditadura, em I972, se encontram, nesse, mas também em outros momentos do filme, com a difícil tarefa de seguir em frente, sem perder a ternura. Ainda com Raymond Williams, o ponto se esclarece.

Um dos efeitos mais imediatos da mobilidade, dentro de uma estrutura que está ela própria em transformação, é a dificuldade na escolha de um cônjuge. [...] O elemento especificamente de classe e os efeitos sobre ele exercidos por uma economia insegura fazem parte da escolha pessoal - que, afinal, é basicamente a escolha de uma forma de vida, de uma identidade na identificação com esta ou aquela pessoa. (WILLIAMS, 20II, p. 348).

Sobre a experiência de Paulo Honório na narrativa fílmica de Hirszman, a qual retoma fraquezas, domínios irredutíveis que se misturam a desesperos e culpas, lembranças de Madalena, destaca-se a passagem em que o proprietário, só, na mesa da grande sala vazia, principia a memória-texto da solidão vindoura. Othon Bastos (Paulo Honório) narra em off, em belíssima sequência marcada pelo som de um metrônomo que desacelera. É compassada a recomposição do tempo, e experiência, memória e linguagem se articulam (SILVA, I985). Othon Bastos ergue o rosto lentamente, até que "o tique-taque do relógio diminui” (RAMOS, I990, p. I02), e nos observa, olho no olho, reinventada também a percepção do nosso próprio lugar naquele momento. E, num instante, Madalena, alvíssima, face descansada e cabelos lindamente asseados, assume o lugar daqueles sentimentos ambíguos: em uma casa-grande da sociedade autoritária brasileira (de I934, I972, e de hoje), eventualmente "sob a forma da tutela e do favor (jamais do direito)" (CHAUI, I986, p. 48): "Madalena [imaginária]: - Precisamos ajudar mestre Caetano. [Paulo Honório]:

29 Caetano Veloso comenta o processo de criação musical para o filme S. Bernardo sobre sequências já então montadas e finalizadas por Leon Hirszman, resultando em vocalizações sobrepostas que lembram o carro de boi, aboios e outros espaços sociais do eito, sob influências africanas e ibéricas do tom lamentoso dos cantos de trabalho do Nordeste do Brasil. Recorda ainda o cantor que dessa experiência surgiria a inspiração para o LP Araçá azul (I973). Cf. S. Bernardo - Extras, 2008.

30 Conferir a passagem no livro S. Bernardo em Ramos, I990, caps. I5 e I6. 
Se eu convencesse Madalena de que ela não tem razão.... Se lhe explicasse que é necessário vivermos em paz... Não me entende. Não nos entendemos” (S. BERNARDO, I972, aprox. IhoImin) ${ }^{3 \text {. }}$.

No filme S. Bernardo há uma direção central de análise: classe, sujeito e relações históricas não se separam naquelas imagens. São três os temas que na parte final do filme enfeixam essa leitura: o rosto de Paulo Honório surgido de dentro da propriedade - sua humanidade proprietária; Madalena santificada pela solidariedade; e o momento em que Paulo Honório nos espreita - o lado da história em movimento.

A primeira sequência que marca esse enredo aparece quando o narrador já traz sem medidas o seu ciúme. Surgem na tela o campo e os gados, e Paulo Honório caminha do fundo daquele plano em direção à câmera, até que o espaço se resplandece do seu rosto, encobrindo a terra e os bichos. Ouvimos então, na voz do ator, sobreposta aos mugidos bovinos, que, "oito metros acima do solo, experimentamos a vaga sensação de ter crescido oito metros", e que, quando "vemos rebanhos numerosos a nossos pés, plantações estirando-se por terras largas, tudo nosso, e avistamos a fumaça que se eleva de casas nossas, onde vive gente que nos teme, respeita e talvez nos ame, porque depende de nós, uma grande serenidade nos envolve" (S. BERNARDO, I972, aprox. Ih26min) ${ }^{32}$.

O plano em que marido e mulher se encontram na igreja é igualmente emblemático. Madalena (o seu nome é referência para a santa dos pecadores arrependidos) dessacraliza aquele espaço: surge santificada, em vida, sem jamais ter praticado o sentimento religioso. Do fundo escuro da igreja, antes que se acenda a vela, ouvimos novamente o aboio/canto de trabalho na voz de Caetano Veloso, e Madalena: "Não tinha proteção, compreende? Além de tudo nossa casa na Levada era úmida e fria. No inverno levava os livros para a cozinha. Podia visitar igrejas? Estudar sempre, sempre, com medo das reprovações" (S. BERNARDO, I972, aprox. Ih38min) ${ }^{33}$.

Por fim, é o olhar de Paulo Honório que nos fita. Na última sequência do longa-metragem, nos espreita do escuro, aí encoberto o fazendeiro. Observamos, e somos por ele observados. O olhar de Hirszman, admirador do cineasta Sergei Eisenstein, soube transformar dificuldades de produção (escassez de película) em recurso de estilo, evocando mesmo os longos planos estáticos daquele mestre russo no filme Ivan, o Terrivel (I944-I958) ${ }^{34}$.

As dificuldades econômicas vividas na região, e aprofundadas no romance, tangenciam a adaptação de Leon Hirszman para S. Bernardo: "vários fregueses que

3I Conferir a passagem no livro S. Bernardo em: Ramos, I990, p. I04.

32 Conferir a passagem no livro S. Bernardo em: Ramos, I990, p. I56. Em Graciliano Ramos, essa narrativa de Paulo Honório se dá no alto do campanário da igreja, a trinta metros de altura. Leon Hirszman aproxima essa distância para oito metros, mais perto de nós, e da propriedade. Comenta Lucia Helena Vianna (I997, p. 30) que Graciliano Ramos teria escrito S. Bernardo entre março e maio de I932 na sacristia e campanário da Igreja de Palmeira dos Índios, o que também faz pensar, simbolicamente, em traços de uma narrativa da confissão nesse romance.

33 Conferir a passagem no livro S. Bernardo em: Ramos, I990, p. I63.

34 Sobre a admiração de Hirzsman por Eisenstein, cf. Rocha, 2003. 
sempre tinham procedido bem quebraram de repente. Houve fugas, suicídios, o Diário Oficial se emprenhou com falências e concordatas" (RAMOS, I990, p. I78). De todo modo, o cineasta, nesse filme, realizado em momento particularmente difícil da ditadura civil-militar no Brasil (apavorante governo Garrastazu Médici), empresta importante fôlego visual para as contradições sociais de que Graciliano Ramos nos fala em sua obra. São do fim da década de I960, início dos anos I970, as imagens dos trabalhadores rurais registrados por Leon Hirszman - tempo que não passa, avesso da ideologia ditatorial do progresso. São pobres moradores em taperas de pau a pique, vestidos em trapos e famintos (S. BERNARDO, I972, aprox. Ih38min), condição conhecida por Paulo Honório na década de I930 e que a ditadura de I964 finge inexistir. Importante ainda observar os movimentos de trabalho registrados pelo cineasta, grupos de agricultores arando a terra e cantando em sistema de mutirão (resistências frente às racionalidades modernizadoras daquele momento), logo após a morte de Madalena, e a insensibilidade do marido: o fazendeiro molesta com um fósforo aceso os seus próprios dedos (S. BERNARDO, I972, aprox. Ih47min).

Graciliano Ramos apresentou em sua obra a dificuldade humana enfrentada na formação da solidariedade numa sociedade móvel e em mutação, a invenção e transformação de sentimentos pela história, questionando determinismos psicológicos: "Não consigo modificar-me, é o que mais me aflige. [...] Creio que nem sempre fui egoísta e brutal. A profissão é que me deu qualidades tão ruins. E a desconfiança terrível que me aponta inimigos em toda a parte! A desconfiança é também consequência da profissão" (RAMOS, I990, p. I87) 35 . Ao fim, o fazendeiro abandona o projeto de S. Bernardo, continuar "para quê? Para quê? Não me dirão? Nesse movimento e nesse rumor haveria muito choro e haveria muita praga" (S. BERNARDO, I972, aprox. Ih49min) ${ }^{36}$. No filme de Leon Hirszman, a presença documental de agricultores e agricultoras (experiências revalorizadas frente a profissões) avança a compreensão de que mudanças históricas, como as que fizeram de Paulo Honório um liberal, precisam lidar com resistências que se articulam de dentro dos conformismos da vida cotidiana: os trabalhadores cantam. Já Paulo Honório: "não canto nem rio" (RAMOS, I990, p. I83).

\section{SOBRE O AUTOR}

NELSON TOMELIN JR. é professor do Departamento de História e do Programa de Pós-Graduação em História da Universidade Federal do Amazonas (UFAM).

E-mail: nelsontomelin@yahoo.com.br.

35 Conferir a passagem no filme S. Bernardo, I972, aprox. Ih5Imin.

36 Conferir a passagem no livro S. Bernardo em: Ramos, I990, p. I8I. 


\section{REFERÊNCIAS}

ALVES, Ricardo L. Pedrosa. Escrever o romance rural. Floema, ano I, n. II, p. I27-I46, jul./dez. 2015. Disponível em: 〈http://periodicos.uesb.br/index.php/floema/article/viewFile/48II/46I2>. Acesso em: 30 maio 2018.

BASTOS, Hermenegildo. Os coronéis - de Mendonça a Paulo Honório: notas sobre tipicidade e realismo em S. Bernardo. Revista do Instituto de Estudos Brasileiros, Brasil, n. 6o, p. I9-33, abr. 20I5. Disponível em: 〈http://www.scielo.br/pdf/rieb/n6o/23I6-90IX-rieb-60-0ooI9.pdf〉. Acesso em: 5 maio 2017.

BENJAMIN, Walter. O narrador, considerações sobre a obra de Nikolai Leskov. In: . Magia e técnica, arte e política. São Paulo: Brasiliense, I996, p. I97-221.

CANDIDO, Antonio. Tese e antítese. São Paulo: Editora Nacional, I978. . Literatura e sociedade: estudos de teoria e história literária. São Paulo: Editora Nacional, I980. Fiç̧ão e confissão: ensaios sobre Graciliano Ramos. Rio de Janeiro: Ouro sobre Azul, 2006. . Depoimento para o Simpósio Graciliano Ramos - 75 anos do livro "Angústia". Universidade de São Paulo, 20II. Disponível em: 〈https://www.youtube.com/watch?v=p3r-dY-oOws 〉. Acesso em: I5 maio 2016.

CANTOS de trabalho: Cacau; Cana-de-açúcar; Mutirão. Direção de Leon Hirszman. Rio de Janeiro: Leon Hirszman Produções, I975-I976. (34 min.), 35 mm, color.

CARDENUTO, Reinaldo. O cinema político de Leon Hirszman (I976-I98I): engajamento e resistência durante o regime militar brasileiro. Tese (Doutorado em Ciências). Programa de Meios e Processos Audiovisuais, Escola de Comunicações e Artes, Universidade de São Paulo, 20I4. Disponível em: <http://www.teses.usp.br/teses/disponiveis/27/27I6I/tde-020220I5-I60846/pt-br.php〉. Acesso em: I9 maio 2017.

CARDOZO, José Eduardo. Resposta à Acusação. Senado Notícias. Brasília: AGU, 20I6. Disponível em: <http://wwwI2.senado.leg.br/noticias/materias/20I6/08/22/veja-os-principais-documentos-doprocesso-de-impeachment-de-dilma-rousseff $>$. Acesso em: Iํ maio $20 I 7$.

CHAUI, Marilena. Apontamentos para uma crítica da Ação Integralista Brasileira. In: CHAUI, Marilena; FRANCO, Maria Sylvia Carvalho. Ideologia e mobilização popular. Rio de Janeiro: Paz e Terra/Cedec, I985.

. Conformismo e resistência: aspectos da cultura popular no Brasil. São Paulo: Brasiliense, I986.

. Cultura e democracia: o discurso competente e outras falas. São Paulo: Cortez, 2003.

COUTINHO, Carlos Nelson. Graciliano Ramos. In: COUTINHO, Carlos Nelson. Literatura e humanismo: ensaios de crítica marxista. Rio de Janeiro: Paz e Terra, I967.

DAVI, Tania Nunes. O cinema de Nelson Pereira dos Santos e Leon Hirszman na (re)leitura de Vidas secas $e$ São Bernardo, de Graciliano Ramos. Tese (Doutorado em História Social). Programa de Pós-Graduação em História, Universidade Federal de Uberlândia, 20Io. Disponível em: <https://repositorio.ufu.br/ bitstream/I23456789/I6287/I/Tese\%20Tania.pdf 〉. Acesso em: 22 maio 2017

DECCA, Edgar S. de. A ciência da produção: fábrica despolitizada. Revista Brasileira de História, v. 3, n. 6, I983.

. I930: o silêncio dos vencidos. São Paulo: Brasiliense, I984.

ELES não usam black-tie. Direção de Leon Hirszman. Rio de Janeiro: Embrafilme, I98I. (I20 min.), 35 $\mathrm{mm}$, color.

FENELON, Déa Ribeiro. O historiador e a cultura popular: história de classe ou história do povo?. História e Perspectivas, Uberlândia, n. 40, p. 27-5I, jan.jun. 2009.

GOLDMAN, Emma. Minha outra desilusão na Rússia. Verve, São Paulo, n. II, p. Io9-I22, 2007. 
Disponível em: 〈https://revistas.pucsp.br/index.php/verve/article/view/5060/3588>. Acesso em: 2 abr. 2017.

GRAMSCI, Antonio. Cadernos do cárcere (volume 4): Temas de cultura, ação católica, americanismo e fordismo. Rio de Janeiro: Civilização Brasileira, 2015.

GRUPO MEMÓRIA POPULAR. Memória popular: teoria, política, método. In: FENELON, Déa Ribeiro et al. (Org.). Muitas memórias, outras histórias. São Paulo: Olho d’Água, 2004, p. 282-295.

HARDMAN, Francisco Foot; LEONARDI, Victor. História da indústria e do trabalho no Brasil: das origens aos anos 20. São Paulo: Global, I982

IMAGENS do inconsciente. Direção de Leon Hirszman. Episódio I - Em busca do espaço cotidiano: Fernando Diniz; Episódio II - No reino das mães: Adelina Gomes; Episódio III - A barca do sol: Carlos Pertuis. Rio de Janeiro: Funarte, I983-I986. (3h45 min.), 35 mm, color.

IVAN, o Terrível. Direção de Sergei Eisenstein. URSS: Mosfilm, I944-I958, (I87 min.), 35 mm, PB.

JUAREZ FILHO, Edmundo. História e alegoria em São Bernardo de Graciliano Ramos. Dissertação (Mestrado em Letras). Departamento de Letras Clássicas e Vernáculas, Faculdade de Filosofia, Letras e Ciências Humanas, Universidade de São Paulo, 2006. Disponível em: <http://www.teses.usp.br/teses/disponiveis/8/8I49/tde-23082007-I3390I/pt-br.php>. Acesso em: 22 maio 2017.

LAFETÁ, João Luiz. O mundo à revelia. In: RAMOS, Graciliano. São Bernardo. Rio de Janeiro: Record, I990. MARX, Karl. Grundrisse. Manuscritos econômicos de I857-I858. Esboços da crítica da economia política. São Paulo: Boitempo; Rio de Janeiro: UFRJ, 20II.

MERLEAU-PONTY, Maurice. O visível e o invisível. São Paulo: Perspectiva, 2005.

MORAES, Dênis de. O velho Graça: uma biografia de Graciliano Ramos. Rio de Janeiro: José Olympio, I992.

OLIVEIRA, Tiago Bernardon de. Anarquismo, sindicatos e revolução no Brasil (I906-I936). Tese (Doutorado em História). Programa de Pós-Graduação em História, Universidade Federal Fluminense, Niterói, 2009. Disponível em: 〈http://historia.uff.br/stricto/td/II42.pdf 〉. Acesso em: Io maio 2017.

PEDREIRA de São Diogo. Hirszman, Direção de Leon Hirszman. In: Cinco vezes favela. Rio de Janeiro: CPC-UNE (Centro Popular de Cultura da União dos Estudantes/Saga Filmes Ltda.), I962. (99 min.), $35 \mathrm{~mm}, \mathrm{~PB}$.

RAMOS, Graciliano. S. Bernardo. Rio de Janeiro: Ariel, I934. . Viventes das Alagoas. São Paulo: Martins Fontes, I970. . Memórias do cárcere. Rio de Janeiro/São Paulo: Record, I978. . Cartas. Rio de Janeiro: Record, I982a. . Infância. Rio de Janeiro: Record, I982b. . São Bernardo. Rio de Janeiro: Record, I990.

. Viagem. Rio de Janeiro: RECORD, 2007.

ROCHA, Glauber. Revisão crítica do cinema brasileiro. São Paulo: Cosac \& Naify, 2003.

SAMUEL, Raphael. Teatros da memória. Projeto História, São Paulo, n. I4, p. 4I-8I, fev. 1997.

S. BERNARDO. Direção de Leon Hirszman. Rio de Janeiro: Saga Filmes Ltda./Mapa Filmes/L. C. Barreto, Embrafilme, I972. (IIO min.), $35 \mathrm{~mm}$, color.

S. BERNARDO - Extras. Vídeo Filmes, Projeto Leon Hirszman 03, 2008. (42 min.), 35 mm, color. Disponível em: 〈https://www.youtube.com/watch?v=MBlMmFTaDIs >. Acesso em: I9 maio 2017.

SILVA, Marcos. O trabalho da linguagem. Revista Brasileira de História, São Paulo, v. 6, n. II, p. 45-6I, I985. THOMPSON, E. P. A miséria da teoria, ou um planetário de erros: uma crítica ao pensamento de Althusser. Rio de Janeiro: Zahar, I98I.

. A formação da classe operária inglesa - v. I. - A árvore da liberdade. Rio de Janeiro: Paz e Terra, I997. 
VESENTINI, Carlos Alberto. A teia do fato: uma proposta de estudo sobre a memória histórica. São Paulo: Hucitec, I997.

VIANNA, Lucia Helena. Roteiro de leitura: São Bernardo, de Graciliano Ramos. São Paulo: Ática, I997.

VIDAS SECAS. Direção de Nelson Pereira dos Santos. Rio de Janeiro: Produções Cinematográficas Herbert Richers S. A., I963. (I03 min.), 35 mm, PB.

WILLIAMS, Raymond. Marxismo e literatura. Rio de Janeiro: Zahar, I979. . Tragédia moderna. São Paulo: Cosac \& Naify, 2002. . O campo e a cidade: na história e na literatura. São Paulo: Companhia das Letras, $20 I r$. 